Review Article

\title{
Experimental Study on the Influence of Aging on Mechanical Properties of Geogrids and Bearing Capacity of Reinforced Sand Cushion
}

\author{
Hui Yuan, ${ }^{1,2}$ Xiaohong Bai $\mathbb{D}^{1},{ }^{1}$ Hehui Zhao, ${ }^{1}$ and Jingren Wang ${ }^{1}$ \\ ${ }^{1}$ College of Architecture and Civil Engineering, Taiyuan University of Technology, Taiyuan 030024, China \\ ${ }^{2}$ Taiyuan City Vocational College, Taiyuan 030027, China
}

Correspondence should be addressed to Xiaohong Bai; bxhong@tyut.edu.cn

Received 9 July 2020; Revised 13 August 2020; Accepted 12 September 2020; Published 8 October 2020

Academic Editor: Qiang Tang

Copyright (c) 2020 Hui Yuan et al. This is an open access article distributed under the Creative Commons Attribution License, which permits unrestricted use, distribution, and reproduction in any medium, provided the original work is properly cited.

\begin{abstract}
Geogrids are widely used in foundation engineering for reinforcing foundations due to their light weight, high strength, and excellent performance. In this study, two kinds of polypropylene biaxial geogrids were used, and indoor thermal oxygen and photooxygen aging tests were carried out. The residual mechanical stability of the exposed materials was determined by tensile testing. The results of both accelerated test methods are discussed and compared in detail. After aging of the geogrid, the trend of tensile strength and fracture elongation change with aging time is obtained. The gray prediction model was used to predict the variation in the retention rate of tensile strength in the geogrid with photooxygen aging time. Model tests of cushions were carried out in a large geogroove to compare the load bearing characteristics of pure sand and the unaged and aged geogrid-reinforced sand cushions. The results show that ultraviolet radiation illuminance plays a decisive role in the aging degree of the polypropylene geogrid. The influence of photooxygen aging on the tensile strength and fracture elongation of a polypropylene biaxial geogrid is greater than that of thermal oxygen aging. Different types of polypropylene biaxial geogrids with photooxygen aging showed different retention rates of tensile strength, and the aging resistance of the geogrid with higher tensile strength was significantly higher than that of the geogrid with lower tensile strength. The tensile strength of the geogrid has an effect on the bearing capacity of reinforced sand cushions. Under proper elongation, the bearing capacity of the reinforced sand cushion is clearly improved compared with that of the unreinforced cushion. The aging behavior of the two geogrids reduces the load bearing capacity of the reinforced cushion by influencing the property of the interface between the geogrid and sand.
\end{abstract}

\section{Introduction}

Geogrids, which are made of polymeric materials, have been used as a construction material for many applications, such as walls, slopes, roads, and building foundations [1]. Geogrid products, which have been used in several civil engineering applications for nearly 40 years, are mostly based on polyolefins, such as polyethylene (PE) or polypropylene (PP). Given that repair or exchange of these products is nearly impossible and the consequences of failure are severe, several applications require service times between 50 and 100 years. Carbon black and antioxidants/stabilizers are used to retard polymer degradation depending on photooxidation and thermal oxidation [2]. However, this is inevitable in the process of production, storage, transportation, and construction. The polymer will be exposed to sunlight, which causes photooxidation aging. Geogrids are expected to eventually experience chemical degradation leading to a reduction in their mechanical properties and change in their chemical and physical properties [3].

The long-term durability of geogrids depends, on the one hand, on their resistance to ultraviolet light and thermal oxidation and, on the other hand, on the loss of stabilizers caused by the specific natural environment and the oxidative consumption of the stabilizer. The long-term durability of a geogrid is governed by its resistance to thermal oxidation and loss of stabilizer by extraction owing to the particular natural environment and oxidative consumption of the stabilizer [4]. 
The time to nominal failure of PP geogrids could be divided into three stages in assessing lifetime: depletion of antioxidants, induction time, and time to reach half-life of a relevant engineering property [3]. Although tests can be conducted at the temperature of specific interest, if the temperature is low, these tests may take many years before there is sufficient change in antioxidants to allow a reliable estimate of the time to depletion. Thus, in many cases, accelerated aging tests are conducted at temperatures above the target temperature [5-12]. Estimation of the expected service lifetimes is then based on the estimation of antioxidant depletion times.

As a plane reinforcing material, a geogrid can provide lateral constraint, improving and reinforcing a soft foundation. The biaxial geogrid has been well understood in improving the bearing capacity and bearing direction of foundations. Many researchers have published scientific research results on bearing capacity and settlement of geogrid reinforced soil. Determining the ultimate bearing capacity of footings resting on reinforced soil is a complex problem, and knowledge of the load-settlement behavior of footings on reinforced soil is limited [13]. The researchers have stated that the parameters identified as critical in improving the bearing capacity include the embedment depth of the reinforcement, number of reinforcement layers, vertical spacing between reinforcement layers, reinforced depth, and width of reinforcement [14]. The engineering performance (CBR) for different types of soil subgrades reinforced with geogrids was studied [15]. Two oxidative induction time (OIT) methods, a standard (Std) OIT test and a high pressure (HP) OIT test, were used to evaluate the interaction of $\mathrm{CB}$ with two types of antioxidants during the oven aging [4]. A fuzzy logic- (FL-) based modeling approach is employed for geogrid-reinforced subgrade soil of unpaved roads [16].

In this study, two different extruded biaxial geogrids were used to test the thermal oxygen aging and photooxidation aging using a xenon lamp weathering test chamber. These two geogrids are biaxial geogrids with the same shape but different ultimate tensile strength. The changes in mechanical properties (especially stress and strain at the rupture point, which is the most sensitive mechanical property with respect to oxidative degradation) were monitored during the aging. Then, a laboratory plane load test of the bearing capacity of a series of reinforced soil foundations was carried out using the aged geogrid. The influence of the aging factors on the bearing capacity of geogrid-reinforced foundations is considered.

\section{Materials and Apparatus}

\subsection{Materials}

2.1.1. Geogrid. After surveying the current market of PPbased geogrid products, two commercially available biaxial geogrids were selected and provided by the manufacturer of Tansa in China. Table 1 lists the corresponding material properties, such as geogrid size, density, and tensile properties.
Basic information about the products, such as the type and amount of the used stabilizer, was not disclosed by the manufacturers. The definition of tensile strength is maximum tensile force divided by (unit) cross section area. As a high concentration of additives might cause problems during manufacturing of the fibers (extruding through a small hole spinneret, cooling, and stretching), antioxidants are mixed into fiber resins in the extrusion process essentially for the purpose of protecting them from oxidation. In addition, all PP biaxial geogrids are UV-stabilized by carbon black with content in the range of $0.5-1 \mathrm{wt} \%$.

2.1.2. Foundation Soil. Natural graded river sand was used for the underlying layer. In the reinforced concrete geogroove $(9 \mathrm{~m} \times 4 \mathrm{~m} \times 3 \mathrm{~m})$, the total thickness of sand laying is $2.4 \mathrm{~m}$. The sand was layered and filled, and each layer was not less than $300 \mathrm{~mm}$. After each layer had been filled, it was fully consolidated three times to ensure that each layer of sand had the same compactness. The improved semiautomatic N63.5 heavy-duty cone dynamic penetration equipment was used to test the compactness of sand in cone dynamic penetration test. The sand is in medium-dense state.

Since the main purpose of this test is to explore the influence of aging on the bearing characteristics of geogrid reinforced soil, in order to avoid the influence of the discreteness of fill on the accuracy of test data, standard sand was used as foundation soil. The standard sand produced by Fujian Nonmetal Mine Co., Ltd. was used as foundation soil. The shear strength index of physical properties of sand for reinforced cushion is as follows: $c=0$ and $\varphi=18.78^{\circ}$, and the relative density is $70 \%$ in the test. See Table 2 for physical indexes of soil.

\subsection{Testing Apparatus}

2.2.1. Aging Test Apparatus. The xenon lamp weathering test chamber is of the SN-150 type, which consists of a xenon lamp illumination system, cooling system, air heating device, air circulation device, rain system, humidity control system, and sensors (temperature, blackboard temperature, and humidity sensors). It can simulate the conditions of light, humidity, rain, condensation, and high temperature in nature and can combine various factors for the weather resistance test.

An important component of the xenon lamp weathering test chamber is the long-arc xenon lamp, which is air-cooled. The working principle of the xenon lamp is as follows: the helium gas in the lamp tube will radiate light energy close to the solar spectrum after being energized. The accuracy error of the three sensors can be controlled at $1 \%$.

The specific technical conditions of the xenon lamp aging test box are as follows: temperature range: $+10^{\circ} \mathrm{C}-80^{\circ} \mathrm{C}, \pm 2^{\circ} \mathrm{C}$; humidity range: $45-90 \%$; rainfall cycle: 1-9999 h; distance between the sample frame and the xenon lamp: $280-370 \mathrm{~mm}$ (adjustable); heating power: $2.5 \mathrm{~kW}$; wet power: $1.5 \mathrm{~kW}$; internal dimensions of the test box: $600 \times 600 \times 600 \mathrm{~mm}$. 
TABLE 1: Physical property indexes of biaxial geogrids.

\begin{tabular}{|c|c|c|c|c|c|c|}
\hline $\begin{array}{l}\text { Sample } \\
\text { code }\end{array}$ & $\begin{array}{c}\text { Grid size } \\
(\mathrm{mm} \times \mathrm{mm})\end{array}$ & $\begin{array}{c}\text { Tensile strength } \\
(\mathrm{kN} / \mathrm{m})\end{array}$ & $\begin{array}{c}\text { Strength at } 2 \% \text { strain } \\
(\mathrm{kN} / \mathrm{m})\end{array}$ & $\begin{array}{c}\text { Strength at } 5 \% \text { strain } \\
(\mathrm{kN} / \mathrm{m})\end{array}$ & $\begin{array}{c}\text { Mass per unit area } \\
\left(\mathrm{kg} / \mathrm{m}^{2}\right)\end{array}$ & $\begin{array}{c}\text { Elongation at } \\
\text { break (\%) }\end{array}$ \\
\hline BG1 & $35 \times 33$ & 15.2 & 6.2 & 11.4 & 0.41 & 12.5 \\
\hline BG2 & $33 \times 32$ & 25.5 & 8.5 & 16.5 & 0.53 & 14.3 \\
\hline
\end{tabular}

TABle 2: Physical indicators of sand for testing.

\begin{tabular}{lccccccc}
\hline Layer & $C_{u}$ & $C_{c}$ & $\rho_{d \max }\left(\mathrm{g} / \mathrm{cm}^{3}\right)$ & $\rho_{d \min }\left(\mathrm{g} / \mathrm{cm}^{3}\right)$ & $d_{60}(\mathrm{~mm})$ & $d_{30}(\mathrm{~mm})$ & $d_{10}(\mathrm{~mm})$ \\
\hline Underlying layer & 5.56 & 1.13 & 1.70 & 1.36 & 0.62 & 0.41 & 0.22 \\
Bearing layer & 1.79 & 0.91 & 1.71 & 1.33 & 0.52 & 0.37 & 0.29 \\
\hline
\end{tabular}

Universal testing machines are used to carry out tensile tests on geogrids with varying degrees of aging. It is mainly used to test forces in metal and nonmetallic materials and performance testing. The universal testing machine is composed of two parts, mechanical transmission system and microcomputer control system. It has high precision and fast response and can achieve real-time recording of test results. Its technical conditions are as follows: load error: $\leq 0.5 \%$, displacement error: $\leq 0.5 \%$, heavy element test: $100 \mathrm{kN}$ of interval selection, load recognition accuracy: $0.01 \mathrm{~N}$, moving speed: $0.001-250 \mathrm{~mm} / \mathrm{min}$, and effective moving distance: $650 \mathrm{~mm}$.

2.2.2. Model Test Apparatus. In order to study the effect of geogrid aging on the bearing characteristics of a geogridreinforced sand cushion, approach the boundary conditions of a field test, and avoid the adverse effects of environmental factors, the laboratory model test site was located in the Laboratory of the Institute of Taiyuan University of Technology. The size is $9 \times 4 \times 3.1 \mathrm{~m}$. The whole test system was composed of the foundation soil material, static servo loading system, test elements, and data acquisition system. As shown in Figure 1, it was loaded by a hydraulic jack. Because of the large amount of sand used in the test and the limited conditions of the test site, local river sand was used as the experimental soil. Before testing, the sand was sieved to remove large particles and impurities. The total thickness of the sandy soil laid in the groove was $2.4 \mathrm{~m}$. In order to ensure the compactness of the sandy soil to meet the test requirements, the sandy soil was layered and tamped with a flat-plate rammer. The thickness of each layer was $0.3 \mathrm{~m}$, and the compaction was fully tamped 3 times to ensure that the compactness of the sandy soil in each layer was the same. A steel rigid plate measuring $200 \mathrm{~mm} \times 200 \mathrm{~mm}$ in plane with $25 \mathrm{~mm}$ thickness was used as a square footing to apply the load. Four dial gauges were set up to measure the settlement of the footing during application of the load. A hydraulic jack loading system was used to apply the load on the geogrid-reinforced sand cushion through the footing plate.

The load was applied through the high-precision static hydraulic servo table produced by Chengdu Servo Hydraulic Equipment Co., Ltd., and the load application level was controlled by the static strain gauge connected with the jack strain sensor. The strain sensor on the top of the jack and the strain gauge adopt the full bridge connection method to control the application of each level of load in the test process according to the calibrated strain load relationship. The hydraulic high precision thrust jack used in vertical loading has a rated load of $100 \mathrm{kN}$.

Increasing static loads were applied by using a hydraulic jack. The load and corresponding footing settlement were measured by a calibrated pressure gauge and four dial gauges, respectively. The testing procedure was performed according to GB50007-2012 [17], where increments of load per unit area were applied and maintained until the rate of settlement was less than $0.1 \mathrm{~mm} / \mathrm{h}$ over two consecutive hours. The test was terminated when the total settlement reached $0.06 \mathrm{~B}$, that is, $12 \mathrm{~mm}$ in this program.

\section{Experimental Procedures}

3.1. Thermal Oxygen Aging. The thermal oxygen aging test, which is also known as the hot air exposure test, artificially accelerates the plastic product or other high molecular polymers using a gravity convection or forced ventilation heat aging test chamber. The principle of the thermal aging test is to expose the sample to a high-temperature environment for a long time by using the high-temperature stability of the oven. The high temperature can shorten the induction period of the oxidatively degradable polymer material. With further increase of time, the crystallinity of the sample increases and the tensile strength, elongation, modulus, and impact strength will change. Then, the changes in the properties before and after aging are compared to determine the degree of aging of the sample. Factors affecting the test data include the temperature control in the test chamber, humidity in the heat aging test chamber, air flow velocity on the surface of the sample, and whether it is affected by periodic rain. It can be seen that many factors affect the test results. All these factors must be precisely controlled to ensure that the error is within acceptable limits.

For thermal oxygen aging, the specimens were aged in a thermostatically regulated xenon lamp weathering test chamber. The dimensions of the working chamber were $600 \mathrm{~mm} \times 600 \mathrm{~mm} \times 600 \mathrm{~mm}$. The aging temperature was achieved and maintained by controlled heating of the working chamber walls. An air ventilation fan in the ceiling of the working chamber forced internal circulation. According to the technical data, there were 10 air changes per hour and a fresh air supply of approximately $10 \mathrm{~m}^{3} / \mathrm{h}$. 


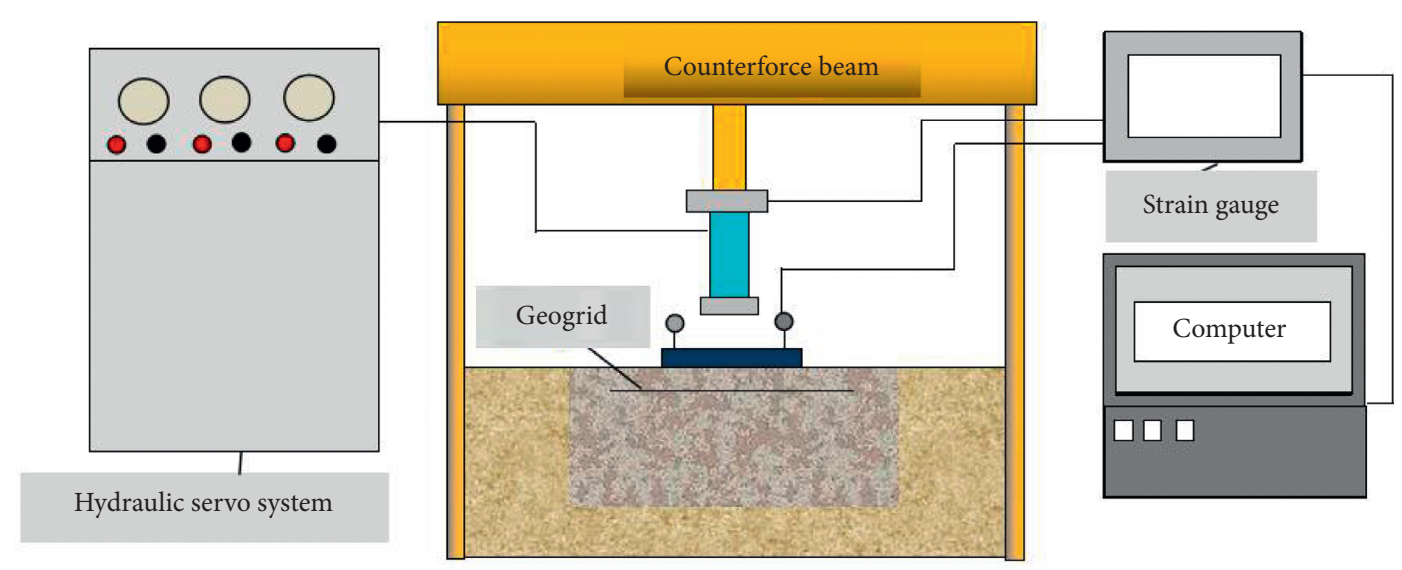

FIGURE 1: Schematic diagram of loading device for the model test.

Square specimens of $50 \times 50 \mathrm{~cm}$ were cut out of the geogrid rolls in the middle at randomly distributed locations.

After comparing the appearance of the geogrid samples aged by thermal oxygen with that of the original geogrid samples, it was found that the color depth of the geogrid samples aged by thermal oxygen for a long time was slightly lighter.

3.2. Photooxygen Aging. In the whole life cycle of geosynthetics, photooxidative aging occurs once they are exposed to sunlight for a long time. Many studies have shown that light is the most important factor causing photooxidation aging. The outdoor exposure test and the indoor light source aging test are the two most important procedures to evaluate the photooxidative aging resistance of geosynthetic materials. The test period required for the outdoor exposure test is long, and the external conditions are complicated and not easy to control. The indoor light source aging test period is short, and it is less interfered by external environmental conditions. It can accurately control the light intensity, temperature, humidity, oxygen concentration, $\mathrm{pH}$, and other conditions, but it does not match the actual engineering environment. The aging time under natural climatic conditions should be found through multiple tests to find out the relationship between the two and establish a conversion formula to predict the service life of the material.

The photooxidation aging test adopts the xenon lamp weathering test chamber. The aging test of geogrid was carried out according to ASTM G154-16 standard [18]. The test box has a built-in rotating sample rack, and a whole grid sample is fixed on the sample rack. The rotation speed is set to 3 cycles/min to ensure uniform illumination and the test is conducted. In the aging process, the cycle illumination mode is adopted. The specific steps are performed for $8 \mathrm{~h}$ under light conditions and then condensed for $4 \mathrm{~h}$ without light, and the cumulative aging time is $700 \mathrm{~h}$. The irradiation intensity was set to $600 \mathrm{~W} / \mathrm{m}^{2}$, the humidity in the test chamber was $70 \% \pm 2 \%$, and the blackboard temperature was $70^{\circ} \mathrm{C}$.

Through observation of the grid sample after fracture, there was a very obvious phenomenon. There was a slight difference in the fracture mode of the grid sample during the tensile test. Figure 2 shows the fracture diagram of the original geogrid and the fracture diagram of the test piece after the photooxygen aging for $700 \mathrm{~h}$.

3.3. Tensile Tests. For the tensile tests, universal testing machines are employed. Multirib and single-rib test methods can be used, and this study uses the single-rib test method. The first step is to determine the tensile rate during the geogrid tensile test. In the case of a fixture clamping the two ends of the geogrid specimen, the distance between the two ends of the fixture is set from 11 to $14 \mathrm{~cm}$. The tensile rate selected in this test is $24 \mathrm{~mm} / \mathrm{min}$. Before the tensile test begins, it is necessary to apply $1 \%$ prestress to calibrate the tensile strength. The measured data includes the tensile strength at peak tension, fracture elongation, and 2\% and 5\% elongation. The longitudinal and transverse ribs are different in mechanical properties. Therefore, the longitudinal and transverse ribs are tested separately to measure the tension of 10 ribs to obtain an average value $f$.

The formula for calculating the geogrid tensile strength is

$$
F=\frac{f \times N}{L \times n},
$$

where $F$ is the tensile strength of the geogrid $(\mathrm{kN} / \mathrm{m}), f$ is the average of the pulling force $(\mathrm{kN}), N$ is the number of ribs on the sample width, $n$ is the number of ribs of the specimen, and $L$ is the width of the sample $(\mathrm{m})$.

Statistical analysis of tensile test data of geogrid is in Table 3. It can be seen from Table 3 that the systematic error of the test results of geogrid tensile test is small and the reliability of the test results is high.

3.4. Model Test. In this test, a replacement test pit with a design size of $600 \mathrm{~mm} \times 600 \mathrm{~mm} \times 600 \mathrm{~mm}$ was excavated. The standard dry sand was laid into the pit layer by layer, and the relative compactness of each layer of each group is ensured to be the same by compacting the constant quality sand to the set height. Calculate the weight of standard dry sand required for each layer with $70 \%$ relative density, and it 


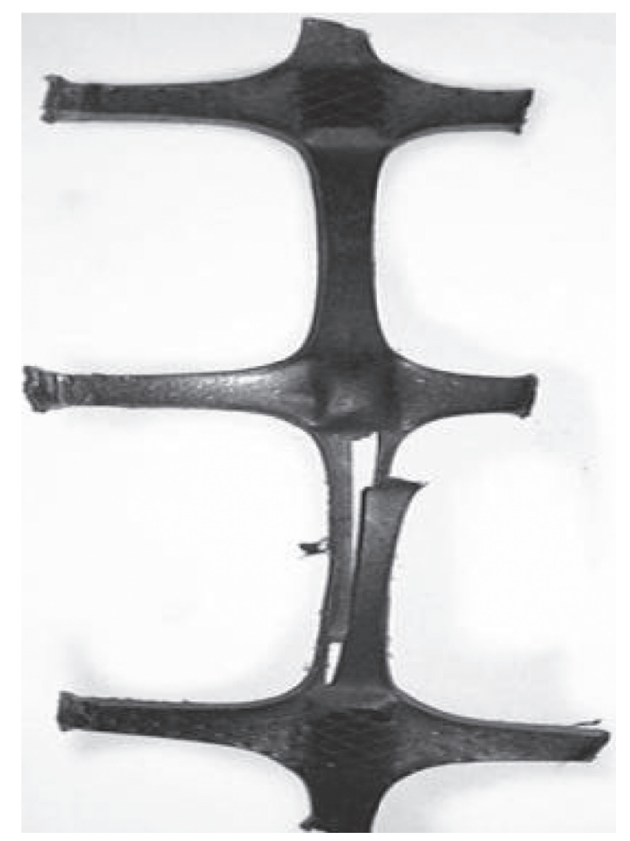

(a)

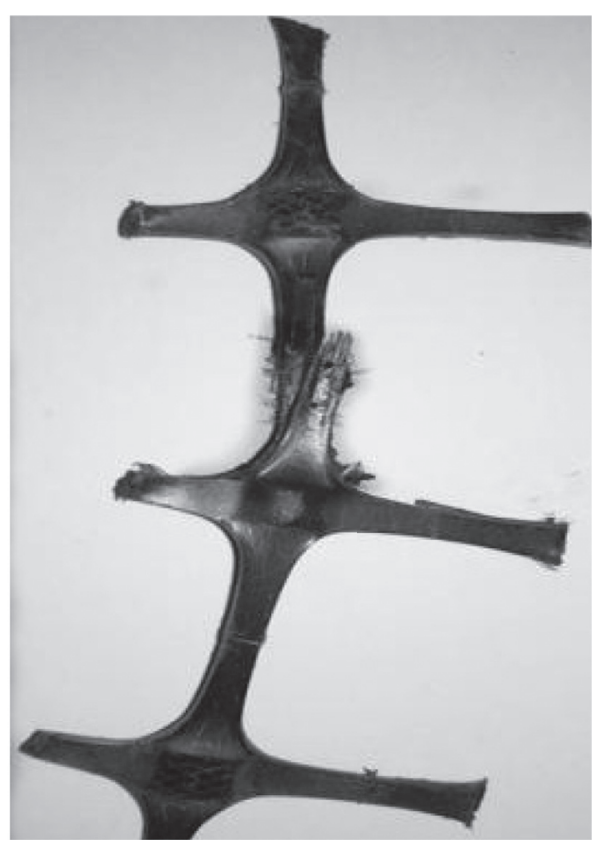

(b)

Figure 2: Tensile fracture diagram of test piece. (a) Original geogrid. (b) Aging geogrid.

TABle 3: Statistical analysis of tensile test data of geogrid.

\begin{tabular}{lccccccccccccccc}
\hline Geogrid & Testing unit & 1 & 2 & 3 & 4 & 5 & 6 & 7 & 8 & 9 & 10 & $\begin{array}{c}\text { Average } \\
\text { value }\end{array}$ & $\begin{array}{c}\text { Standard } \\
\text { deviation }\end{array}$ & $\begin{array}{c}\text { Coefficient of } \\
\text { variation }\end{array}$ \\
\hline BG1 & $\begin{array}{c}\text { Tensile } \\
\text { strength } \\
\text { Elongation at } \\
\text { break }\end{array}$ & 15.21 & 15.32 & 15.33 & 15.21 & 15.22 & 15.23 & 14.91 & 15.22 & 15.23 & 15.31 & 15.22 & 0.1126 & 0.0074 \\
\hline BG2 & $\begin{array}{c}\text { Tensile } \\
\text { strength } \\
\text { Elongation at } \\
\text { break }\end{array}$ & 25.43 & 12.53 & 12.62 & 12.51 & 12.41 & 12.62 & 12.51 & 12.72 & 12.52 & 12.33 & 12.52 & 0.1098 & 0.0088 \\
\hline & 14.34 & 14.25 & 14.42 & 14.21 & 14.43 & 14.54 & 14.33 & 14.32 & 14.21 & 14.23 & 14.33 & 0.1037 & 0.0073 \\
\hline
\end{tabular}

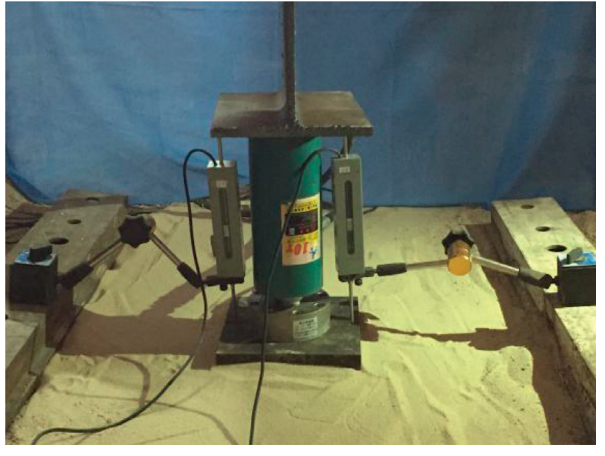

(a)

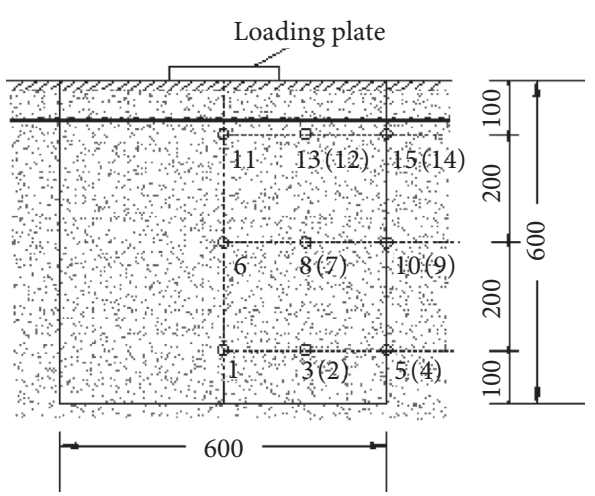

(b)

FIgURE 3: The picture of the model test site and the layout of the Earth pressure box. (a) Picture of the model test site. (b) Layout of soil pressure box. 


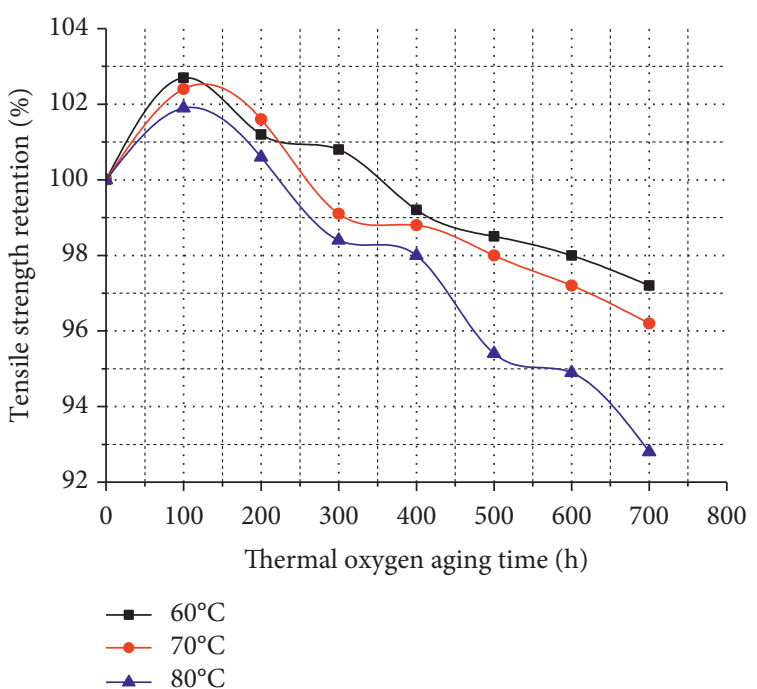

(a)

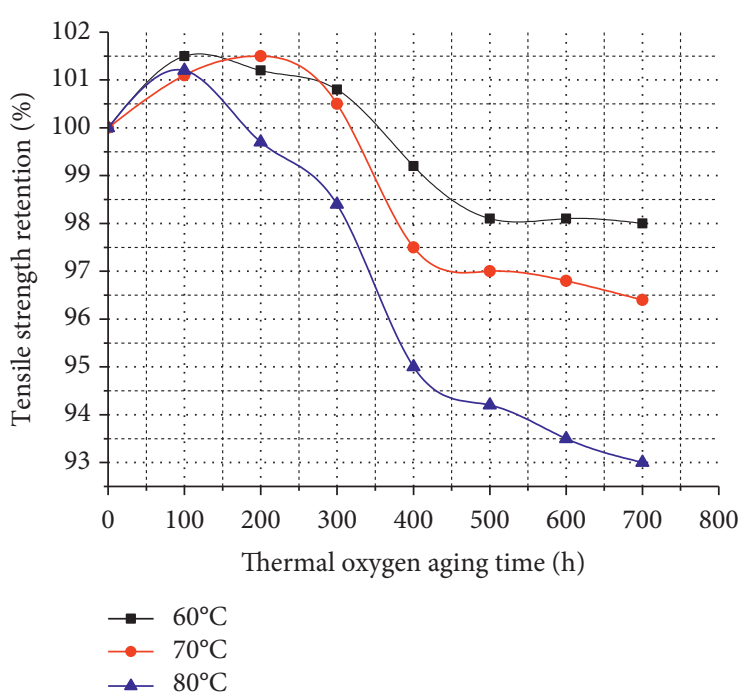

(b)

FIGURE 4: Relationship curves of tensile strength retention rate-thermal aging time. (a) BG1. (b) BG2.

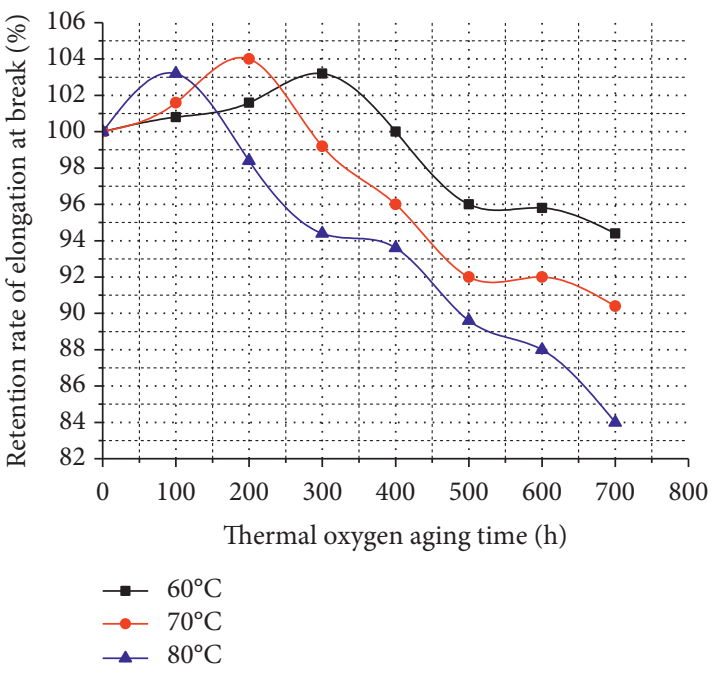

(a)

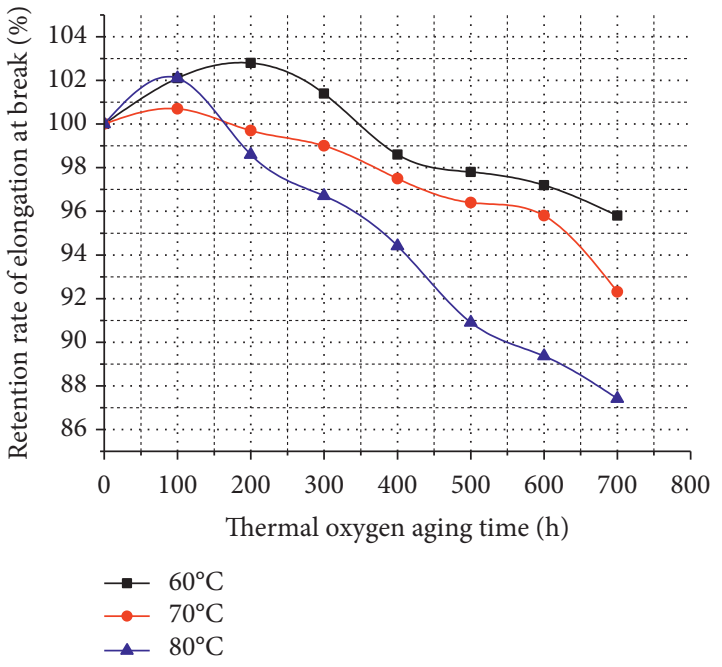

(b)

FIGURE 5: Relationship curves of elongation at break-thermal aging time. (a) BG1. (b) BG2.

is laied in the soil pit and compacted to the thickness of $50 \mathrm{~mm}$ for each layer. The geogrid is laid at a depth of $70 \mathrm{~mm}$ under the loading plate and fixed with $U$-nails. The picture of the model test site and the layout of the Earth pressure box are shown in Figure 3.

\section{Results and Discussion}

The thermal oxygen and photooxygen aging will result in the reduction in mechanical properties of the geogrid. The mechanical properties of the geogrid with aging parameters are described by the tensile strength retention rate and fracture elongation retention rate. The retention rate of tensile strength is the ratio between the tensile strength of the aged geogrid and the tensile strength of the geogrid before aging, expressed as a percentage. The fracture elongation retention rate is the ratio of the aged fracture elongation to the preaging fracture elongation, expressed as a percentage.

\subsection{Geogrid Aging}

4.1.1. Thermal Oxygen Aging Test. The results of the thermal oxygen aging test for samples BG1 and BG2 of the biaxial geogrid of PP are shown in Figures 4 and 5. In Figure 4, the results show relatively small differences for different aging time (at least for temperatures of 60 and 70 degrees) and aging time 


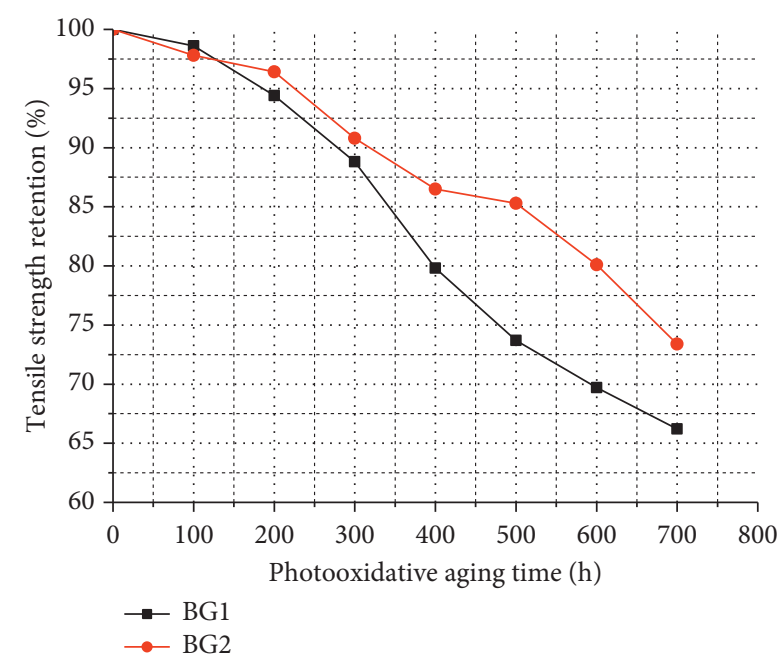

FIGURE 6: Relationship curves of tensile strength retention ratephotooxidation aging time.

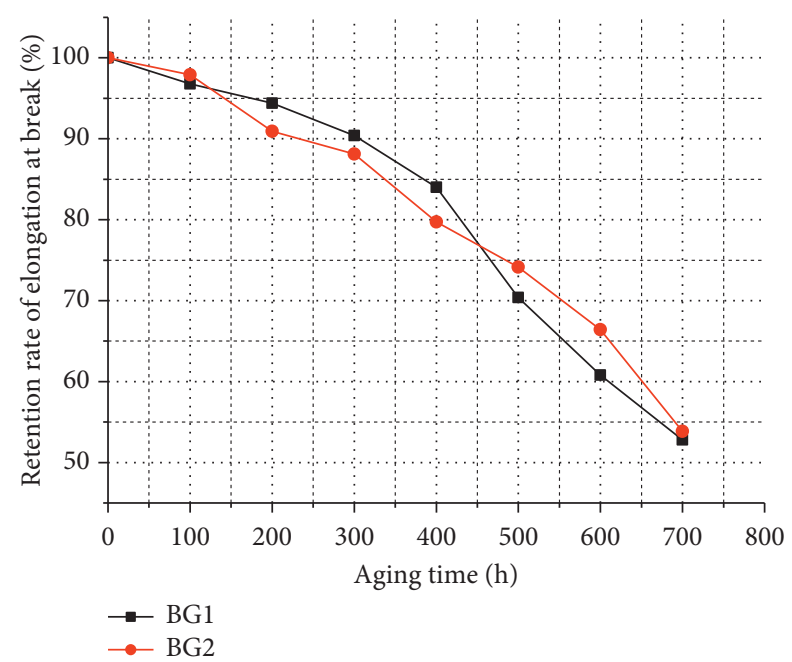

Figure 7: Relationship curves of retention rate of elongation at break-photooxidation aging time.

up to 400 hours. In Figure 5(a), the results show that the elongation at break of the PP biaxial geogrid increases slightly in the early stage of thermal oxygen aging, and the higher the temperature is, the shorter the increase period is. At $60^{\circ} \mathrm{C}$ and $70^{\circ} \mathrm{C}$, the influence of thermal oxygen aging on tensile strength and fracture elongation is not obvious. The tensile test of longitudinal and transverse ribs has been carried out by the authors. The test results show that the tensile test results of longitudinal and transverse ribs are not different.

Comparing samples BG1 and BG2 of the two grids, it can be found that the temperature is $80^{\circ} \mathrm{C}$, and the tensile strength retention rates of samples BG1 and BG2 are $92.8 \%$ and $94.3 \%$, respectively, when aging is of $700 \mathrm{~h}$. The retention rates of BG1 and BG2 fracture elongation were $84 \%$ and $87.41 \%$, respectively, when aging is of $700 \mathrm{~h}$. The experimental results show that the tensile strength and fracture elongation of BG1 and BG2, which are both biaxial geogrids of $\mathrm{PP}$, have similar trends with thermal oxygen aging time.

4.1.2. Photooxygen Aging Test. The relationship between tensile strength retention rate and photooxygen aging time of two kinds of geogrid is obtained by the indoor ultraviolet photooxygen aging test (Figure 6). It can be seen in Figure 6 that the two curves have the same trend; that is, with the increase in photooxygen aging time, the tensile strength of the two kinds of PP biaxial geogrids shows a significant trend of decrease. After $300 \mathrm{~h}$ aging time, the BG1 starts to decline at greater rate than BG1, and the difference at the end of the test is $>10 \%$. Figure 7 shows the relationship between the fracture elongation retention rate and photooxygen aging time of the two geogrids. It can be seen from Figure 7 that, within $400 \mathrm{~h}$, the fracture elongation retention rate of the two geogrids alternately declines with the photooxygen aging time. At the photooxygen aging time of $700 \mathrm{~h}$, the fracture elongation retention rates of samples $B G 1$ and $B G 2$ are not significantly different.

4.1.3. Comparative Analysis. Figure 8 shows the relationship of tensile strength retention rate between the thermal oxygen aging and the photooxygen aging specimens with aging time at $70^{\circ} \mathrm{C}$.

Figure 9 shows the relationship of retention rate of elongation at break between the thermal oxygen aging and the photooxygen aging specimens with aging time at $70^{\circ} \mathrm{C}$. It can be seen that, under the conditions of thermal oxygen aging, the curves of tensile strength and fracture elongation retention rates with aging time of samples BG1 and BG2 are relatively gentle. However, the tensile strength and fracture elongation retention curves with aging time are steeper under photooxygen aging conditions. The thermal oxygen aging intensity is reduced by no more than $5 \%$, while the photooxygen aging intensity is reduced by about 35\%, and thus the impact of photooxygen aging is much greater than that of thermal oxygen aging. It is shown that the effect of light on the geogrid tensile strength during aging is much greater than that of temperature.

4.1.4. Prediction Model. The gray system theory proposed by Professor Deng (China) in 1982 has been widely used in economic, social, and engineering fields. It has advantages of smooth degree of data and a good precision [19]. Based on the gray prediction model (GM), by using a small amount of raw data and simple modeling calculation, the future data can be predicted and the accuracy meets the research needs. In this study, eight groups of data of tensile strength and elongation at rupture obtained from the photooxidation 


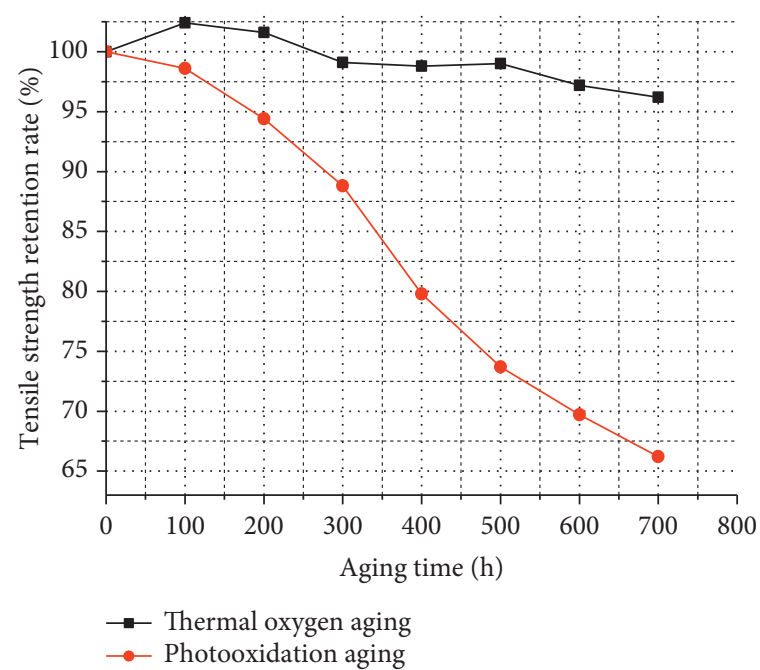

(a)

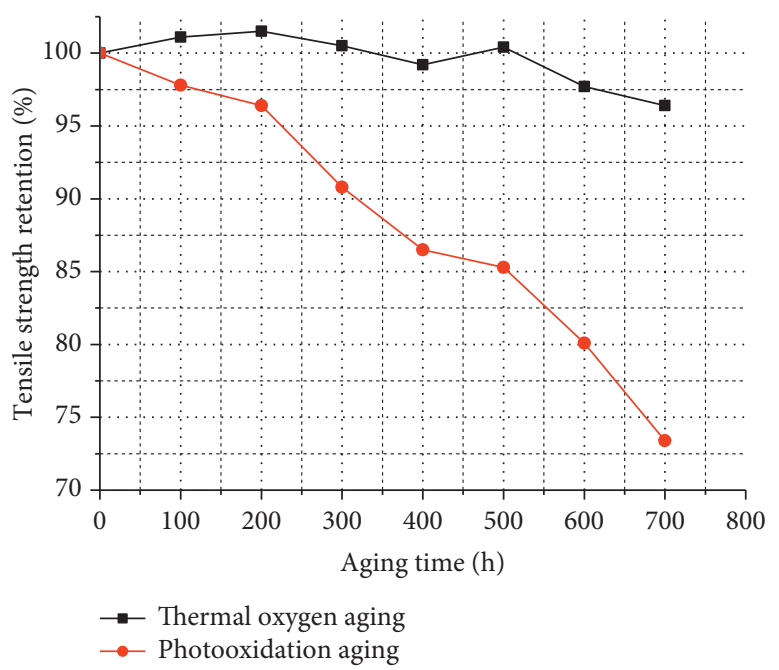

(b)

FIGURE 8: Relationship curves of tensile strength retention rate-aging time. (a) BG1. (b) BG2.

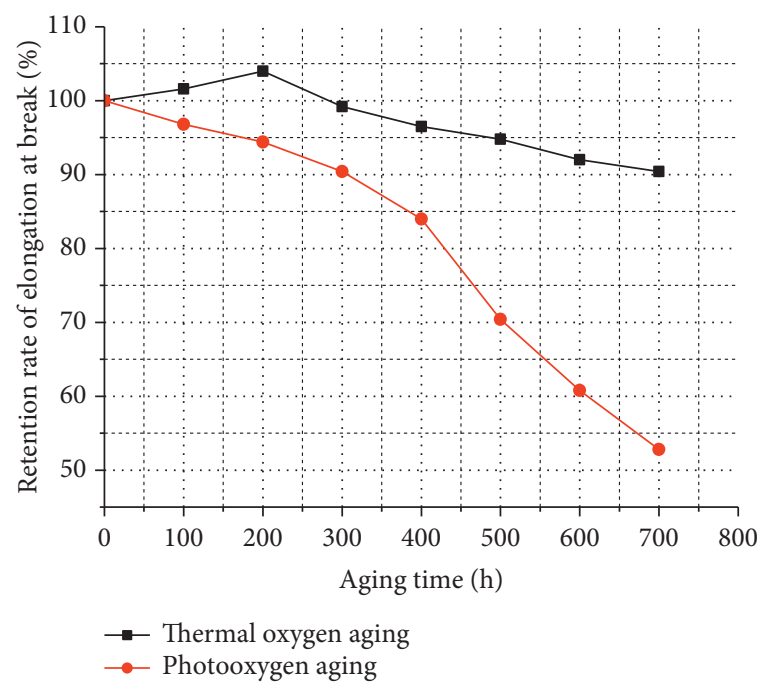

(a)

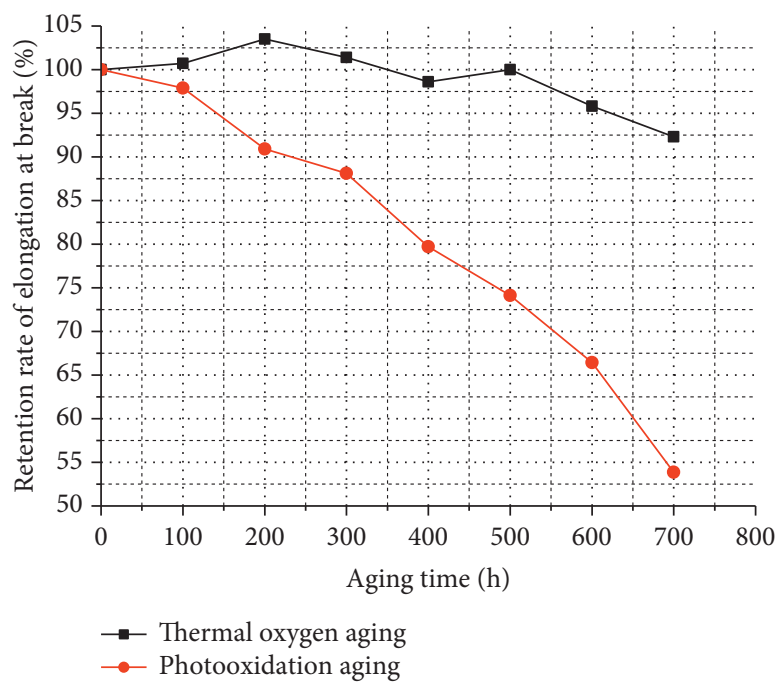

(b)

FIGURE 9: Relationship curves of retention rate of elongation at break-aging time. (a) BG1. (b) BG2.

aging test of PP biaxial geogrids were provided. The GM was used to fit the photooxidative aging test results of PP biaxial geogrids, and the failure rule of PP biaxial geogrids under indoor photooxidative aging is inferred.

Gray model is a differential equation established by generating new data series from the original data series. GM $(1, N)$ represents the differential equation of $N$ variables of order 1 . The modeling process is as follows:

Sequence based on more than four known pieces of data is

$$
\left\{X^{(0)}(k)\right\}, \quad k=1,2,3, \ldots, n .
$$

Generating sequence of accumulated data with given data sequence is as follows:

$$
\left\{X^{(1)}(k)\right\}, \quad k=1,2,3, \ldots, n .
$$

Approximating cumulative data series values with continuous smooth values of exponential curves is as follows:

$$
\tilde{X}^{(1)}(k)=\left[\widetilde{X}^{(1)}(1)-\frac{u}{a}\right] \bullet e^{-a(k-1)}+\frac{u}{a}, \quad k=1,2,3, \ldots, n .
$$

The smoothing approximation value of the original data sequence is reduced:

$$
\widetilde{X}^{(0)}(k)=\widetilde{X}^{(1)}(k)-\widetilde{X}^{(1)}(k-1), \quad k=1,2,3, \ldots, n .
$$

In the above formula, 
TABLE 4: The results of gray model prediction.

\begin{tabular}{|c|c|c|c|c|c|c|c|c|}
\hline Aging time (h) & & 0 & 100 & 200 & 300 & 400 & 500 & 600 \\
\hline \multirow{3}{*}{ BG1 tensile strength retention rate } & Test value $(\%)$ & 100 & 98.6 & 94.4 & 88.8 & 79.80 & 73.7 & 69.7 \\
\hline & Predicted value (\%) & 100 & 100.1 & 93.1 & 86.6 & 80.5 & 74.8 & 69.5 \\
\hline & Relative error (\%) & - & 1.52 & 1.38 & 2.48 & 0.88 & 1.49 & 0.29 \\
\hline \multirow{3}{*}{ BG2 tensile strength retention rate } & Test value $(\%)$ & 100 & 97.8 & 96.4 & 90.8 & 86.5 & 85.3 & 80.1 \\
\hline & Predicted value (\%) & 100 & 98.70 & 94.81 & 91.08 & 87.49 & 84.04 & 80.73 \\
\hline & Relative error (\%) & - & 0.92 & 1.65 & 0.30 & 1.14 & 1.48 & 0.78 \\
\hline
\end{tabular}

$$
\begin{aligned}
{\left[\begin{array}{l}
a \\
u
\end{array}\right] } & =\left(B^{T} B\right)^{-1} B^{-1} B^{T} Y_{n}, \\
B & =\left[\begin{array}{ll}
b_{1} & 1 \\
b_{2} & 1 \\
\cdots & 1 \\
b_{n-1} & 1
\end{array}\right], \\
Y_{n} & =\left[\begin{array}{c}
y_{1} \\
y_{2} \\
\cdots \\
y_{n-1}
\end{array}\right], \\
m & =(n-1) \sum_{i=1}^{n-1}\left(b_{i}\right)^{2}-\left(\sum_{i=1}^{n-1} b_{i}\right)^{2}, \\
u & =\frac{\left[-\sum_{i=1}^{n-1} b_{i} \sum_{i=1}^{n-1} b_{i} y_{i}+\sum_{i=1}^{n-1}\left(b_{i}\right)^{2} \sum_{i=1}^{n-1} y_{i}\right]}{m} . \\
& =\frac{\left[(n-1) \sum_{i=1}^{n-1} b_{i} y_{i}-\sum_{i=1}^{n-1} b_{i} \sum_{i=1}^{n-1} y_{i}\right]}{m},
\end{aligned}
$$

Based on the experimental data of tensile strength and elongation at rupture of PP biaxial geogrids under photooxidation aging, a GM was established to predict the changes in tensile strength and elongation at rupture of PP biaxial geogrids under long-term photooxidation aging. The prediction results are listed in Table 4.

It can be seen from Table 3 that the GM $(1,1)$ model is established for the tensile strength of samples BG1 and BG2 under photooxidation aging for $0-600 \mathrm{~h}$. The maximum relative error of fitting the photooxidation aging test results of BG1 is only $2.48 \%$, the average error is only $1.49 \%$, and the tensile strength retention rate of BG1 and BG2 under $700 \mathrm{~h}$ is only $66.2 \%$. The GM is used to predict the tensile strength of BG1 and BG2. The calculated predicted value is $64.6 \%$, and the relative error of data recovery is only $2.42 \%$. The maximum relative error of fitting BG2 is only $1.65 \%$, the average error is only $0.30 \%$, and the relative error of checking data with $700 \mathrm{~h}$ is only $5.65 \%$. This clearly shows that the GM $(1,1)$ model has better fitting effect.
Prediction curves of tensile strength and photooxidation aging time are shown in Figure 10. It can be seen from Figure 10(a) that the tensile strength retention rate of BG1 is $51.98 \%$. When the photooxidation aging time is $1000 \mathrm{~h}$, the tensile strength retention rate of BG1 is $48.32 \%$. When the photooxidation aging time is $1100 \mathrm{~h}$, the tensile strength retention rate of BG1 is less than $50 \%$, so the PP biaxial geogrid losees efficacy. From Figure 10(b), it can be seen that the tensile strength retention rate of BG2 is $51.88 \%$ when the photooxidation aging time is $1700 \mathrm{~h}$ and $49.83 \%$ when it is $1800 \mathrm{~h}$, less than $50 \%$, and thus the PP biaxial geogrid is invalid.

The aging test curve changes greatly in the early stage of aging and is relatively unstable. The prediction curve is not very accurate in the early stage of aging but rather accurate in describing the long-term performance of aging.

4.2. Test of Load Bearing Capacity of Reinforced Sand Foundation considering the Effects of Aging. The tensile strength of the geogrid before and after aging is listed in Table 5.

Load-settlement curves of the cushion are obtained according to load at all levels, as shown in Figure 10. Compared with the nonreinforced sand cushion, the settlement value of the reinforced sand cushion under the same load decreases and the bearing capacity of the foundation increases; the settlement value of the reinforced sand cushion of BG2 geogrid was smaller than that of the reinforced sand cushion of BG1 geogrid, and the bearing capacity of the cushion was increased; the difference in the load-settlement curves of the reinforced sand cushion and the nonreinforced sand cushion at the early stage was small. It shows that the reinforcement effect was not obvious at the initial stage of loading. With the increase in load, the spacing between the load-settlement curves of the pure sand, BG1 reinforced sand, and BG2 reinforced sand cushions gradually increased. Thus, the reinforcement effect is increasingly obvious.

The P-S curve of geogrid-reinforced sand considering the aging effect is shown in Figure 11. Figures 11(a) and 11(b) show that the P-S curves of aging geogrids coincide with those of nonaging geogrids when the load $P$ was less than $125 \mathrm{kPa}$. With the increase in load, the two P-S curves begin to separate, and, under the same load, the settlement ratio of the aging-reinforced sand cushion of the BG1 geogrids to that of the non-aging-reinforced sand cushion was less than that of the aging-reinforced sand cushion. In general, the bearing capacity of the aging-reinforced cushion was slightly lower than that of the non-aging- 


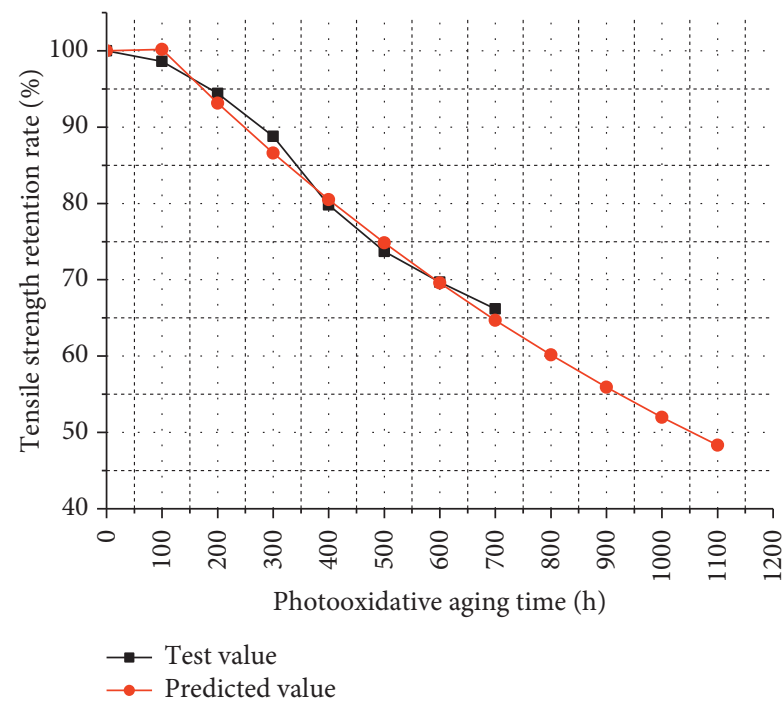

(a)

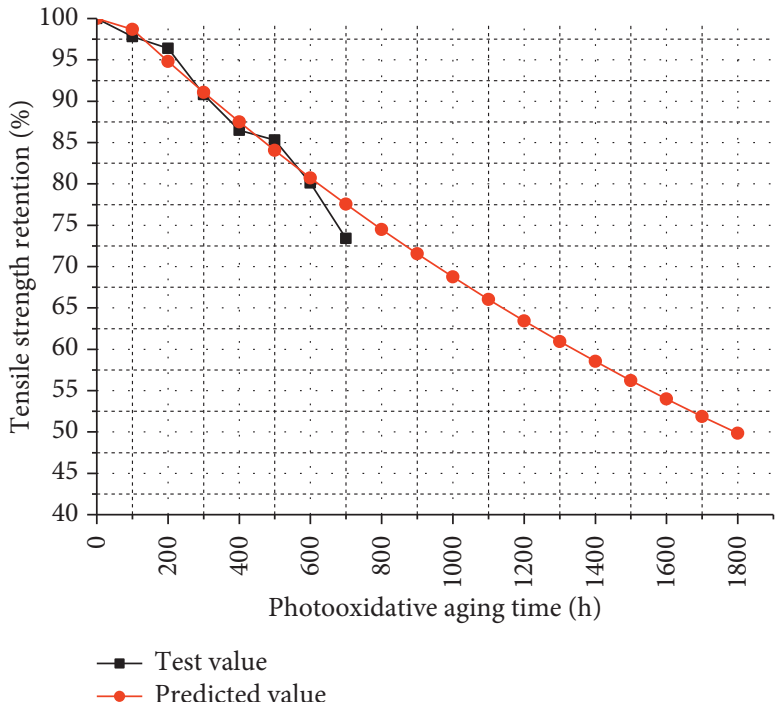

(b)

FIgURe 10: Prediction curves of tensile strength and photooxidation aging time. (a) BG1. (b) BG2.

TABLE 5: The tensile strength of geogrid before and after aging.

\begin{tabular}{lcccc}
\hline Geogrid & $\begin{array}{c}\text { Tensile strength of geogrid before aging } \\
(\mathrm{kN} / \mathrm{m})\end{array}$ & $\begin{array}{c}\text { Radiation intensity (W/ } \\
\left.\mathrm{m}^{2}\right)\end{array}$ & $\begin{array}{c}\text { Tensile strength of geogrid after aging of } \\
700 \mathrm{~h}\end{array}$ & $\begin{array}{c}\text { Aging time } \\
(\mathrm{h})\end{array}$ \\
\hline BG1 & 15.8 & 600 & 10.8 & 700 \\
BG2 & 25.5 & 600 & 18.35 & 700 \\
\hline
\end{tabular}

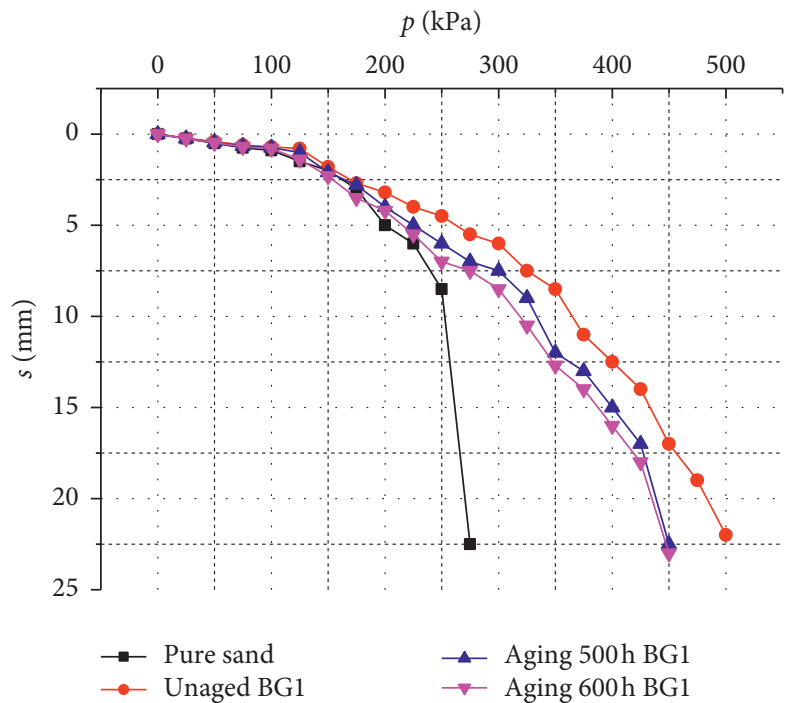

(a)

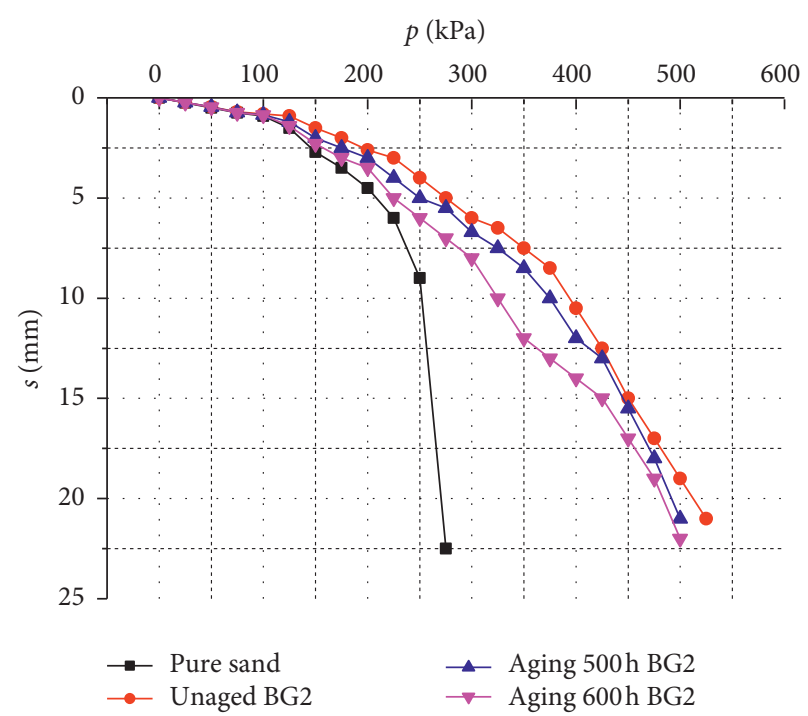

(b)

FIGURE 11: Load-settlement (P-S) curve of geogrid reinforced sand considering aging effect. (a) BG1. (b) BG2.

reinforced cushion, but the effect is not obvious. The bearing capacity of reinforced soil decreases with the increase of aging time.

The effect of aging of geogrids in the early stage of loading on the bearing capacity of reinforced soil is negligible. The authors define an aging effect on the initial load. When the load value is less than the initial load of aging effect, the aging effect is small on the settlement of foundation. When the load value exceeds the initial load of aging effect, the aging effect on the settlement of foundation 


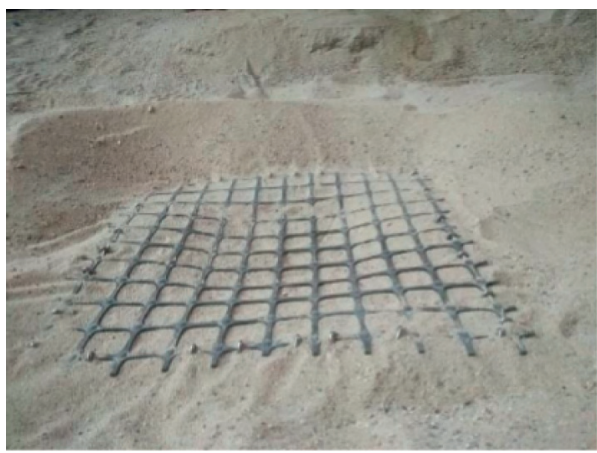

(a)

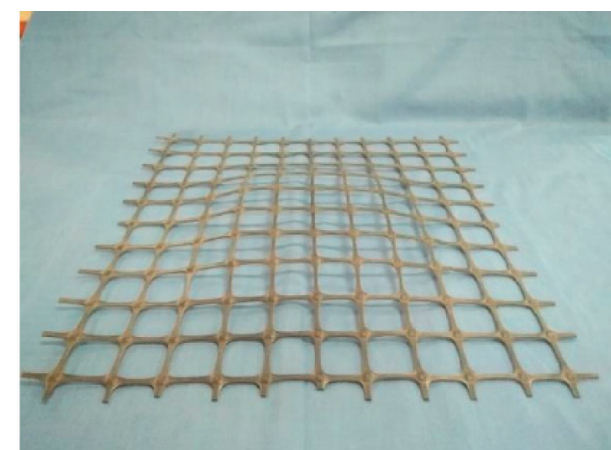

(b)

FIGURE 12: Geogrid-reinforced foundation damage

TABLE 6: BCR of geogrid-reinforced sand.

\begin{tabular}{lcccc}
\hline Group & Aging time & Ultimate bearing capacity $(\mathrm{kPa})$ & BCR & Percentage reduction in strength due to aging \\
\hline Unreinforced & - & 250 & 1 & - \\
BG1 & 0 & 375 & 1.5 & - \\
BG1 & 500 & 325 & 1.3 & 13.33 \\
BG1 & 600 & 300 & 1.2 & 20 \\
BG2 & 0 & 400 & 1.6 & - \\
BG2 & 500 & 375 & 1.5 & 6.25 \\
BG2 & 600 & 325 & 1.3 & 18.75 \\
\hline
\end{tabular}

gradually appears. For BG1, the aging load has an initial value of $125 \mathrm{kPa}$. Similar to BG1, the initial aging load of BG2 bars is $175 \mathrm{kPa}$, which is much larger than that of BG1 bars (Figure 11(b)). The aging effect of BG2, with higher tensile strength on the initial load, is greater than that of the BG1 geogrid, with lower tensile strength. It indicates that the aging effect of BG2, with higher tensile strength, on the bearing capacity of the reinforced cushion foundation is smaller than that of the BG1 geogrid, with lower tensile strength.

After the model test, it was found that the deformation of biaxial geogrid was significant (see Figure 12). The deformed geogrid was measured, and the central point of the biaxial geogrid shall be concave, about $17 \mathrm{~mm}$.

The beneficial effect of reinforcement for increasing the bearing capacity is conveniently described by the bearing capacity ratio (BCR), according to [20]

$$
\mathrm{BCR}=\frac{q_{R}}{q_{0}}
$$

In order to compare the strengths of geogrids under different load levels, the ultimate bearing capacity and ultimate bearing capacity ratio are listed in Table 6 . It can be seen that the bearing capacity of the geogrid-reinforced cushion decreases with aging. For BG1, the bearing capacity of the foundation decreases by $13.33 \%$ and $20 \%$, respectively, after $500 \mathrm{~h}$ and $600 \mathrm{~h}$ of aging. For BG2 aged $500 \mathrm{~h}$ and $600 \mathrm{~h}$, the bearing capacity of the foundation decreases by $6.25 \%$ and $18.75 \%$, respectively.

The BCR of the geogrid-reinforced sand is listed in Table 6 . It can be seen that the aging effect of the geogrid leads to the decline of the reinforced foundation BCR, which reduces the bearing capacity of the geogrid-reinforced foundation. For different types of geogrids, the degree of decline in BCR owing to aging is different, and the value of decline in BCR owing to aging is slightly smaller for the higher-strength BG2 than for the lower-strength BG1.

\section{Mechanism Analysis of Photooxygen Aging in PP Biaxial Geogrid}

The energy of the ultraviolet light accelerates the aging process of the grid. Photooxidation causes degradation and aging of the PP germanium geogrid, decomposes the PP polymer, and destroys its internal structure [21]. The tensile strength and fracture elongation of two kinds of PP biaxial geogrids were reduced in different degrees after different aging modes, temperature, aging time, and aging conditions. After thermal aging, there is a decrease in crosslinking degree and in binding and friction between molecular chains. The effects of photooxygen aging are greater than the effects of thermal oxygen aging. The sunlight ultraviolet light provides the energy required for chemical crosslinking of the PP biaxial geogrid. The tensile strength and fracture elongation of the geogrid temporarily increase in a short period of time (100-200 h), with the extension of aging time.

\section{Conclusion}

In this study, thermal oxygen test is carried out at $60^{\circ} \mathrm{C}, 70^{\circ} \mathrm{C}$, and $80^{\circ} \mathrm{C}$ and ultraviolet photooxygen aging tests are carried out at $70^{\circ} \mathrm{C}$ for two kinds of PP biaxial geogrids of different 
specifications. The influence of aging factors on the bearing capacity of geogrid-reinforced foundations is considered.

After investigating the effects of thermal oxygen and photooxygen aging tests on tensile strength and fracture elongation of geogrids, the following conclusions are drawn:

(1) The tensile strength of the geogrid decreases with the increase in aging time, and there is an increase in properties in aging period up to 100-200 hours. The comparison with the same thermal oxygen aging time shows that the tensile strength of the geogrid decreases with the increase in thermal oxygen aging temperature. With the increase in photooxygen aging time, the tensile strength of the geogrid showed a significant trend of decrease. The effect of ultraviolet light on the geogrid tensile strength during aging is much greater than that of temperature. The effect of photooxygen aging on tensile strength is greater than that of thermal oxygen aging for two different types of PP biaxial geogrid. Under the same temperature and aging time, the tensile strength of geogrid is reduced by no more than $5 \%$, while the strength of geogrid is reduced by about $35 \%$.

(2) The retention rate of fracture elongation decreases with the increase in thermal oxygen aging temperature and aging time. The elongation at break decreases with the photooxygen aging time, and the influence of ultraviolet light on geogrid fracture elongation is much greater than that of temperature. The tensile strength retention rate of different types of PP biaxial grids showed different photooxygen aging characteristics. The aging resistance performance of BG2 was significantly higher than that of BG1.

(3) The effect against tensile strength retention rate is better with the GM. The following conclusion came from prediction models: with a blackboard temperature of $70^{\circ} \mathrm{C} \pm 2^{\circ} \mathrm{C}$, irradiation of $8 \mathrm{~h}$, nonirradiated condensation of $4 \mathrm{~h}$, relative humidity of $70 \% \pm 2 \%$, and ultraviolet irradiance of $600 \mathrm{~W} / \mathrm{m}^{2}$, the lower-intensity BG1 fails at approximately $1100 \mathrm{~h}$. The higher-strength BG2 fails at approximately $1800 \mathrm{~h}$.

(4) Geogrid reinforcement significantly changes the bearing characteristics of a sand cushion by increasing the bearing capacity of the reinforced cushion. The reinforcement effect of the geogrid with higher tensile strength is more significant. Aging changes the interface characteristics between the geogrid and soil. In this test, the bearing properties of the geogrid cushion after aging have certain changes. The aging behavior of the two geogrids reduces the load bearing capacity of the reinforced cushion by $20 \%$ and $18.75 \%$, respectively.

\section{Data Availability}

No data were used to support this study.

\section{Conflicts of Interest}

The authors declare that they have no conflicts of interest related to this work.

\section{Acknowledgments}

The authors would like to acknowledge the National Natural Science Foundation of China for the financial support for this study (no. 51578359).

\section{References}

[1] Y.-L. Dong, J. Han, and X.-H. Bai, "Numerical analysis of tensile behavior of geogrids with rectangular and triangular apertures," Geotextiles and Geomembranes, vol. 29, no. 2, pp. 83-91, 2011.

[2] A. M. R. Ewais, R. K. Rowe, and J. Scheirs, "Degradation behaviour of HDPE geomembranes with high and low initial high-pressure oxidative induction time," Geotextiles and Geomembranes, vol. 42, no. 2, pp. 111-126, 2014.

[3] Y. G. Hsuan and R. M. Koerner, "Antioxidant depletion lifetime in high density polyethylene geomembranes," Journal of Geotechnical and Geoenvironmental Engineering, vol. 124, no. 6, pp. 532-541, 1998.

[4] W.-K. Wong and Y. G. Hsuan, "Interaction of antioxidants with carbon black in polyethylene using oxidative induction time methods," Geotextiles and Geomembranes, vol. 42, no. 6 , pp. 641-647, 2014.

[5] R. K. Rowe and H. P. Sangam, "Durability of HDPE geomembranes," Geotextiles and Geomembranes, vol. 20, no. 2, pp. 77-95, 2002.

[6] H. P. Sangam and R. K. Rowe, "Effects of exposure conditions on the depletion of antioxidants from high-density polyethylene (HDPE) geomembranes," Canadian Geotechnical Journal, vol. 39, no. 6, pp. 1221-1230, 2002.

[7] W. Müller and I. Jacob, "Oxidative resistance of high density polyethylene geomembranes," Polymer Degradation and Stability, vol. 79, pp. 161-172, 2003.

[8] S. B. Gulec, T. B. Edil, and C. H. Benson, "Effect of acidic mine drainage on the polymer properties of an HDPE geomembrane," Geosynthetics International, vol. 11, no. 2, pp. 60-72, 2004.

[9] R. K. Rowe and S. Rimal, "Depletion of antioxidants from a HDPE geomembrane in a composite liner," Journal of Geotechnical and Geoenvironmental Engineering, vol. 134, no. 1, pp. 68-78, 2008.

[10] R. K. Rowe, S. Rimal, and H. P. Sangam, "Ageing of HDPE geomembrane exposed to air, water and leachate at different temperatures," Geotextiles and Geomembranes., vol. 27, pp. 131-151, 2009.

[11] R. K. Rowe, M. Z. Islam, and Y. G. Hsuan, "Effects of thickness on the aging of HDPE geomembranes," Journal of Geotechnical and Geoenvironmental Engineering, vol. 136, no. 2, pp. 299-309, 2010.

[12] F. B. Abdelaal and R. K. Rowe, "Effect of high temperatures on antioxidant depletion from different HDPE geomembranes," Geotextiles and Geomembranes, vol. 42, no. 4, pp. 284-301, 2014.

[13] X.-H. Bai, X.-Z. Huang, and W. Zhang, "Bearing capacity of square footing supported by a geobelt-reinforced crushed stone cushion on soft soil," Geotextiles and Geomembranes, vol. 38, pp. 37-42, 2013. 
[14] S. Jahandari, J. Li, M. Saberian, and M. Shahsavarigoughari, "Experimental study of the effects of geogrids on elasticity modulus, brittleness, strength, and stress-strain behavior of lime stabilized kaolinitic clay," GeoResJ, vol. 13, pp. 49-58, 2017.

[15] U. Rajesh, S. Sajja, and V. K. Chakravarthi, "Studies on engineering performance of geogrid reinforced soft subgrade," Transportation Research Procedia, vol. 17, pp. 164-173, 2016.

[16] M. Singh, A. Trivedi, and S. K. Shukla, "Fuzzy-based model for predicting strength of geogrid-reinforced subgrade soil with optimal depth of geogrid reinforcement," Journal of Transportation Infrastructure Geotechnology, vol. 33, p. 1, 2020.

[17] Chinese Ministry of Housing and Urban-Rural Development, "Key points for shallow plate load testing," Code for Design of Building Foundation GB50007-2012, p. 87, Chinese Ministry of Housing and Urban-Rural Development, Beijing, China, 2012.

[18] ASTM G154-16, Standard Practice for Operating Fluorescent Ultraviolet (UV) Lamp Apparatus for Exposure of Nonmetallic Materials, American Society for Testing Materials, West Conshohocken, PA, USA, 2016.

[19] J. L. Deng, "Control problems of grey systems," Systems \& Control Letters, vol. 1, no. 5, pp. 288-294, 1982.

[20] J. Binquet and K. L. Lee, "Bearing capacity analysis on reinforced earth slabs," Journal of Geotechnical Engineering Division, vol. 101, pp. 1257-1276, 1975.

[21] K. Grabmayer, G. M. Wallner, S. Beißmann et al., "Characterization of the aging behavior of polyethylene by photoluminescence spectroscopy," Polymer Degradation and Stability, vol. 107, pp. 28-36, 2014. 